\title{
Low prevalence of vitamin $D$ deficiency in adult residents in Hainan, the tropical island province of China
}

\author{
Leweihua Lin ${ }^{1} \wedge$, Qianying Ou ${ }^{1}$, Lu Lin ${ }^{1}$, Huachuan Zhang ${ }^{1}$, Kaining Chen ${ }^{1}$, Daoxiong Chen $^{1}$, Huibiao Quan ${ }^{1}$, \\ Yangli $\mathrm{He}^{2}$, Tuanyu Fang ${ }^{1 \wedge}$ \\ ${ }^{1}$ Department of Endocrinology, Hainan General Hospital, Hainan Affiliated Hospital of Hainan Medical University, Haikou, China; ${ }^{2}$ Department of \\ Health Care Centre, Hainan General Hospital, Hainan Affiliated Hospital of Hainan Medical University, Haikou, China \\ Contributions: (I) Conception and design: Le Lin, T Fang; (II) Administrative support: T Fang; (III) Provision of study materials or patients: \\ All authors; (IV) Collection and assembly of data: Q OU, H Zhang, H Quan; (V) Data analysis and interpretation: Le Lin, T Fang, Y He; (VI) \\ Manuscript writing: All authors; (VII) Final approval of manuscript: All authors. \\ Correspondence to: Tuanyu Fang. Department of Endocrinology, Hainan General Hospital, Hainan Affiliated Hospital of Hainan Medical University, \\ Haikou, China. Email: fangtuanyu_2010@163.com; Yangli He. Department of Health Care Centre, Hainan General Hospital, Hainan Affiliated \\ Hospital of Hainan Medical University, Haikou, China. Email: 1669413518@qq.com; Huibiao Quan. Department of Endocrinology, Hainan \\ General Hospital, Hainan Affiliated Hospital of Hainan Medical University, Haikou, China. Email: quanhuibiao@aliyun.com.
}

Background Vitamin D deficiency is considered to be a global health problem. The purpose of this study was to evaluate the prevalence of vitamin D deficiency and analyze its related factors among adult residents in Hainan, a tropical island province of southern China.

Methods: A total of 1,700 healthy adults, aged 18-86 years (617 men and 1,073 women), were enrolled in our cross-sectional descriptive study. Binomial logistic regression analyses were performed to identify possible predictors of vitamin D status.

Results: The average serum 25-hydroxyvitamin D [25(OH)D] concentration was $37.66 \pm 10.77 \mathrm{ng} / \mathrm{mL}$ (males $43.60 \pm 11.8 \mathrm{ng} / \mathrm{mL}$, females $34.20 \pm 8.40 \mathrm{ng} / \mathrm{mL}$; I $<0.001$ ). The proportions of vitamin $\mathrm{D}$ sufficiency $[25(\mathrm{OH}) \mathrm{D} \geq 30 \mathrm{ng} / \mathrm{mL}]$, insufficiency $[20 \mathrm{ng} / \mathrm{mL} \leq 25(\mathrm{OH}) \mathrm{D}<30 \mathrm{ng} / \mathrm{mL}]$, and deficiency [25(OH)D $<20 \mathrm{ng} / \mathrm{mL}$ ] were $76.6 \%, 20.5 \%$, and $2.9 \%$, respectively. Vitamin D deficiency in the young, middleaged, and elderly groups were $4.2 \%, 2.7 \%$, and $1.7 \%$, respectively. Vitamin D sufficiency was found to be positively associated with male sex $(\mathrm{P}<0.0001)$, age $>40$ years $(\mathrm{P}=0.014)$, habitation in a rural area $(\mathrm{P}<0.0001)$, summer/autumn seasons $(\mathrm{P}<0.0001)$, and having $<13$ years of formal education $(\mathrm{P}<0.0001)$.

Conclusions: Our study was the first to assess the vitamin D status and analyze related factors among adult residents in Hainan Province, China. We found that vitamin D deficiency has low prevalence in this population, suggesting that before developing a strategy for the clinical use of vitamin D supplements in a region, the levels of vitamin $\mathrm{D}$ in generally healthy populations of that region should be assessed, to avoid unnecessary supplementation.

Keywords: Vitamin D; 25-hydroxyvitamin D [25(OH)D]; tropical island; China; age

Submitted Mar 26, 2021. Accepted for publication May 13, 2021.

doi: 10.21037/apm-21-1033

View this article at: http://dx.doi.org/10.21037/apm-21-1033

^ ORCID: Leweihua Lin, 0000-0002-4756-2292; Tuanyu Fang, 0000-0002-0359-6394. 


\section{Introduction}

Vitamin D (calciferol) is an essential fat-soluble secosteroid that regulates the levels of calcium and phosphate, and plays a critical role in calcium homeostasis and skeletal health. In addition, vitamin D figures prominently in autoimmune diseases, cancer, metabolic syndromes, cardiovascular diseases, infections, and all causes of mortality (1-3). Serum 25-hydroxyvitamin D [25(OH)D] has been proposed as a good indicator of vitamin D stores and as the best approach for assessing vitamin D status in humans (4). In recent years, a large number of global epidemiological data have shown that there is an extremely high prevalence of vitamin D deficiency in adults (5-9). Surprisingly, in the Middle East and India, regions with abundant sunshine, the prevalence of vitamin $\mathrm{D}$ deficiency in adults is as high as $30 \%$ to $96.3 \%(10-12)$. In inland China, the prevalence of vitamin $\mathrm{D}$ deficiency in adults in cities at different latitudes is as high as $31.3 \%$ to $87.1 \%(6,13,14)$. Hainan Province, at the southernmost tip of China, is located latitude $18^{\circ} 10^{\prime} \mathrm{N}-20^{\circ} 10^{\prime} \mathrm{N}$, which is Chinese only low-latitude tropical island province with a tropical monsoon climate, and is rich in ultraviolet radiation throughout the year, which is conducive to vitamin D production in humans. However, the environment, air pollution, desire for skin whitening leading to increased use of sun-shading methods, and daily routines of leaving early and returning late, may lead to a decrease in sunlight exposure to the skin (15), thereby affecting the vitamin $\mathrm{D}$ level of residents in Hainan Province. To our knowledge, few studies have examined the vitamin D status of adult residents in Hainan Province. Therefore, our study aimed to evaluate vitamin D status and its related factors in adult residents in Hainan. We present the following article in accordance with the STROBE reporting checklist (available at http://dx.doi.org/10.21037/ apm-21-1033).

\section{Methods}

\section{Study population and etbics}

Survey participants aged 18-86 years were recruited from a project led by Hainan General Hospital from 2018 to 2020 to better understand several health problems in Hainan, the tropical island province of China. All participants were selected by a stratified random cluster sampling. In the first phase, 3 cities and 3 rural locations were selected as survey sites by a simple random sampling method. In the second phase, 2 village committees and 2 neighborhood committees from each site were chosen using the population proportional sampling method. In the final stage, qualified participants who met the inclusion criteria were randomly chosen from selected neighborhood committees or village committees. The composition of age and sex of each committee and urban-rural ratio were decided based on China's 2010 national census data (16). All participants were ethnically East Asian Han residents distributed across the province and had lived in the selected region for $>5$ years. The exclusion criteria were as follows: (I) history of acute or chronic infections, digestive system diseases, renal disease, metabolic and endocrine diseases, nutritional diseases, rheumatic diseases, or malignant tumors; (II) history of circulatory disease; (III) history of surgery, medication, blood donation, or blood transfusion within the previous 6 months; (IV) intake of vitamin D supplements or other drugs that could have affected bone metabolism within the past 1 year; (V) pregnant or breastfeeding within the previous year; and (VI) early menopause ( $<40$ years old).

A total of 1,700 adult residents were included, and their blood samples were collected to detect serum 25(OH)D. The present study was approved by the Ethics Committee of Hainan General Hospital [Medical ethics research (2018) no.78]. The study was in accordance with the Declaration of Helsinki (as revised in 2013). All participants gave written informed consent.

\section{Demographic characteristics assessment}

For each participant, a trained investigator conducted a detailed questionnaire survey to collect information about social demographic characteristics, education level, medical history, lifestyle risk factors, history of chronic diseases, and personal medical history. The blood collection month was used to record the season. We defined the seasons according to the Chinese lunar calendar. The summer-autumn season was from May 16 to November 15, and the winter-spring season was November 16 to May 15.

\section{Antbropometric and clinical assessment}

Body weight, height, and waist circumference of the participants were measured by trained investigators according to standard procedures. Values for weight and height were kept to the nearest $0.1 \mathrm{~kg}$ and $0.1 \mathrm{~cm}$, respectively. Body mass index was calculated by dividing body weight in $\mathrm{kg}$ by the square of height in meters $\left(\mathrm{m}^{2}\right)$. Underweight status was defined as a body mass index of 
lower than 18.5, normal status was defined as a body mass index of 18.5 to 23.9 , overweight status was defined as a body mass index of 24 to $<28$, and obese status was defined as a body mass index of 28 or higher for both men and women (17). Waist circumference was measured at the midpoint between the lateral iliac crest and lowest rib to the nearest $0.1 \mathrm{~cm}$. Central obesity was defined as a waist circumference of $90 \mathrm{~cm}$ or greater for men and $80 \mathrm{~cm}$ or greater for women (11). The participants were stratified into the 3 following groups according to their age: youth (18-39 years old), middle-aged (40-59 years old), and elderly ( $\geq 60$ years old).

\section{Laboratory measurements}

Fasting blood samples were collected in the morning. Serum 25(OH)D concentration was measured using the electro chemiluminescent immunoassay (ECLIA) in a Cobas ${ }^{\circledR}$ e601 platform (Roche Diagnostics GmbH, Basel, Switzerland) according to the manufacturer's protocol. The test ranges of $25(\mathrm{OH}) \mathrm{D}$ were $3.0-70.0 \mathrm{ng} / \mathrm{mL}(1 \mathrm{ng} / \mathrm{mL}$ $=0.4 \mathrm{nmol} / \mathrm{L})$. The interassay coefficient of variation was $6 \%$, and the intraassay coefficient of variation was $4 \%$.

\section{Criteria of vitamin D deficiency}

Circulating $25(\mathrm{OH}) \mathrm{D}$ concentrations were divided into 4 subgroups according to the criteria of the Endocrine Society guidelines: severely deficient $(\leq 10 \mathrm{ng} / \mathrm{mL})$, deficient ( $\leq 20 \mathrm{ng} / \mathrm{mL})$, insufficient $(20-30 \mathrm{ng} / \mathrm{mL})$, and sufficient $(\geq 30 \mathrm{ng} / \mathrm{mL})(18)$.

\section{Statistical analysis}

All statistical analyses were conducted using SPSS Statistics 23.0 (IBM Corp., Armonk, NY, USA). The baseline characteristics were presented using means with the standard deviations and frequencies with percentages for categorical variables. Characteristics of different groups were compared by Student's $t$-test, chi-square test, or analysis of variance (ANOVA). Rank correlation coefficients were calculated for serum $25(\mathrm{OH}) \mathrm{D}$ and urban-rural living differences, season, or educational level, and other biochemical markers, after adjustments were made for age and sex. A binomial logistic regression was used to evaluate possible predictors of vitamin $\mathrm{D}$ sufficiency. All reported $\mathrm{P}$ values were 2 -tailed, and a $\mathrm{P}$ value of $<0.05$ was considered statistically significant.

\section{Results}

\section{Subject characteristics}

A total of 1,690 healthy individuals (617 males and 1,073 females; 814 urban residents and 876 rural residents) were enrolled and analyzed in our study, and participants with severe hemolytic serum samples or unqualified data were excluded. The mean age of the participants was $48.34 \pm 13.46$ years old (range, $18-86$ years old). The average body mass index, waist circumference, total cholesterol, and triglyceride levels were $23.76 \pm 3.63 \mathrm{~kg} / \mathrm{m}^{2}, 80.95 \pm 9.93 \mathrm{~cm}$, $5.42 \pm 1.10 \mathrm{mmol} / \mathrm{L}$, and $1.92 \pm 1.88 \mathrm{mmol} / \mathrm{L}$, respectively. No significant differences in sex ratio within age, urban-rural living or seasons subgroups were observed (all $\mathrm{P}>0.05$ ). The average age, body mass index, waist circumference, total cholesterol, and triglyceride levels of the participates with a high education level ( $\geq 13$ years) were lower than those with a low education level $(<13$ years; all $\mathrm{P}<0.05$; Table 1$)$.

\section{$25(\mathrm{OH}) \mathrm{D}$ status and the prevalence of vitamin $\mathrm{D}$ deficiency}

The serum 25(OH)D levels for participants in different subgroups are presented in Table 2. Among the population in the low-latitude tropical island province of China, the mean serum $25(\mathrm{OH}) \mathrm{D}$ level was $37.66 \pm 10.77 \mathrm{ng} / \mathrm{mL}$. The mean serum 25(OH)D levels were significantly higher in males than in females $(\mathrm{P}<0.001)$. Mean serum 25(OH)D levels differed by age and tended to increase with age, with the highest levels in the elderly group ( $\geq 60$ years old) and significantly lower levels in the younger group (18-39 years old). Mean serum 25(OH)D levels in urban residents were significantly lower than those in rural residents $(\mathrm{P}<0.001)$. Mean serum 25(OH)D levels were higher in participants whose blood was taken during the summer-autumn season than in those whose blood was taken during the winterspring season $(\mathrm{P}<0.001)$. Mean serum 25(OH)D levels were lower in participants with a high education level $(\geq 13$ years $)$ compared to those with a low education level $(<13$ years; $\mathrm{P}<0.001)$.

Mean serum 25(OH)D levels in participants with central obesity were lower than in those with a normal waist circumference $(\mathrm{P}=0.015)$. Mean serum 25(OH) $\mathrm{D}$ levels in participants with hypercholesterolemia or hypertriglyceridemia were higher than those with normal blood lipid levels. There were no statistical differences among participants with different body mass indices $(\mathrm{P}=0.075$; Table 2).

In 2018-2020, $0(0 \%), 49(2.9 \%), 346(20.5 \%)$, and 
Table 1 Overall baseline characteristics of participants $(x \pm S D, n=1,690)$

\begin{tabular}{|c|c|c|c|c|c|c|c|}
\hline Variable & $\mathrm{n}$ & Male (\%) & Mean age (year) & BMI $\left(\mathrm{kg} / \mathrm{m}^{2}\right)$ & Waist circumference $(\mathrm{cm})$ & $\begin{array}{l}\text { Total cholesterol } \\
(\mathrm{mmol} / \mathrm{L})\end{array}$ & $\begin{array}{c}\text { Triglycerides } \\
\text { (mmol/L) }\end{array}$ \\
\hline Total & 1,690 & $617(36.5)$ & $48.34 \pm 13.46$ & $23.76 \pm 3.63$ & $80.95 \pm 9.93$ & $5.42 \pm 1.10$ & $1.92 \pm 1.88$ \\
\hline Male & 617 & - & $49.26 \pm 13.01$ & $24.35 \pm 3.33$ & $85.52 \pm 9.31$ & $5.47 \pm 1.06$ & $2.26 \pm 2.16$ \\
\hline $18-39$ & 477 & $155(32.5)$ & $31.29 \pm 5.29$ & $22.75 \pm 3.71$ & $76.63 \pm 10.05$ & $4.95 \pm 0.95$ & $1.68 \pm 1.37$ \\
\hline $40-59$ & 860 & $322(38.6)$ & $50.40 \pm 5.29$ & $24.16 \pm 3.26$ & $82.30 \pm 9.18$ & $5.57 \pm 1.10$ & $2.09 \pm 2.34$ \\
\hline$\geq 60$ & 353 & $130(36.6)$ & $66.37 \pm 5.194$ & $24.13 \pm 4.07$ & $83.50 \pm 9.72$ & $5.66 \pm 1.10$ & $1.84 \pm 0.92$ \\
\hline \multicolumn{8}{|l|}{ Season } \\
\hline Sumer-Autumn & 1,244 & $453(36.4)$ & $48.39 \pm 13.30$ & $23.80 \pm 3.47$ & $80.64 \pm 9.83$ & $5.44 \pm 1.12$ & $2.00 \pm 2.03$ \\
\hline Winer-Spring & 446 & $164(36.8)$ & $48.21 \pm 13.91$ & $23.62 \pm 4.03$ & $81.80 \pm 10.14$ & $5.37 \pm 1.02$ & $1.71 \pm 1.37$ \\
\hline \multicolumn{8}{|l|}{ Education level } \\
\hline Low (<13 years) & 1,221 & $411(33.7)$ & $52.28 \pm 11.99$ & $23.97 \pm 3.53$ & $81.76 \pm 9.58$ & $5.51 \pm 1.11$ & $1.99 \pm 2.06$ \\
\hline High ( $\geq 13$ years) & 469 & $206(43.9)$ & $38.10 \pm 11.56$ & $23.18 \pm 3.79$ & $78.84 \pm 10.49$ & $5.17 \pm 1.03$ & $1.73 \pm 1.29$ \\
\hline
\end{tabular}

BMI, body mass index.

1,295 (76.6\%) of adult residents in Hainan were classified as severely vitamin $\mathrm{D}$ deficient $(\leq 10 \mathrm{ng} / \mathrm{mL})$, vitamin $\mathrm{D}$ deficient $(<20 \mathrm{ng} / \mathrm{mL})$, insufficient $(20-30 \mathrm{ng} / \mathrm{mL})$, and sufficient $(\geq 30 \mathrm{ng} / \mathrm{mL})$, respectively. Females showed a significantly higher prevalence of vitamin $\mathrm{D}$ deficiency $(4.2 \%)$ compared with males $(0.6 \%, \mathrm{P}<0.001)$. The prevalence of vitamin $\mathrm{D}$ deficiency decreased with age. Vitamin D deficiency was significantly higher in the younger group $(4.2 \%)$ compared with the middle-aged group $(2.7 \%)$ and the elderly group $(1.7 \%, \mathrm{P}<0.001)$. Residents living in urban areas (5.2) had a higher prevalence of vitamin $\mathrm{D}$ deficiency than did those living in rural areas $(0.8 \%, \mathrm{P}<0.001)$. The prevalence of vitamin $\mathrm{D}$ deficiency was lower in the summer-autumn season $(1.0 \%)$ compared with the winter-spring season $(8.1 \%, \mathrm{P}<0.001)$. The prevalence of vitamin $\mathrm{D}$ deficiency in residents with a high education level (4.5\%) was higher than those with a lower education level $(2.3 \%, \mathrm{P}<0.001)$. The prevalence of vitamin $\mathrm{D}$ deficiency in participants with hypercholesterolemia or hypertriglyceridemia was lower than those with normal blood lipid levels $(\mathrm{P}<0.001)$. No significant difference was found in the prevalence of vitamin $\mathrm{D}$ deficiency among the body mass index or waist circumference subgroups $(\mathrm{P}>0.05$; Table 2).

\section{Association between 25(OH)D and other related biomarkers}

Significant differences in age, gender, urban or rural living, season, educational level, and waist circumference were observed when participants were stratified by $25(\mathrm{OH})$ D status (Table 3). Rank correlation analysis revealed that age was significantly negatively correlated with $25(\mathrm{OH})$ $\mathrm{D}(\mathrm{r}=-0.395 ; \mathrm{P}<0.01)$. After adjusting for age and sex, the rank correlation analysis showed that urban or rural living, season, education level, and waist circumference were corelated with $25(\mathrm{OH}) \mathrm{D}$ level $(\mathrm{r}=0.203,-0.266$, -0.211 , and -0.059 , respectively; $\mathrm{P}<0.05$ ), whereas $\mathrm{BMI}$, total cholesterol, and triglycerides had no significant relationship with $25(\mathrm{OH}) \mathrm{D}$ levels $(\mathrm{r}=0.043,0.014$, and 
Table 2 Serum $25(\mathrm{OH}) \mathrm{D}$ levels $\left(\bar{x}_{ \pm} \mathrm{SD}\right)$ and prevalence of vitamin $\mathrm{D}$ deficiency $[\mathrm{n}(\%)]$ in the different subgroups

\begin{tabular}{|c|c|c|c|c|c|c|c|c|c|}
\hline Variable & $\begin{array}{c}25(\mathrm{OH}) \mathrm{D} \\
(\mathrm{ng} / \mathrm{mL})\end{array}$ & $\mathrm{F} / \mathrm{t}$ & $P$ & \multicolumn{4}{|c|}{$25(\mathrm{OH}) \mathrm{D}$} & $\chi^{2}$ & $P$ value \\
\hline Total & $37.66 \pm 10.77$ & - & - & $1,295(76.6)$ & $346(20.5)$ & $49(2.9)$ & $0(0)$ & - & - \\
\hline Gender & & 17.373 & 0.000 & & & & & 95.463 & 0.000 \\
\hline Male & $43.60 \pm 11.8$ & & & $554(89.8)$ & $59(9.6)$ & $4(0.6)$ & $0(0)$ & & \\
\hline Age groups (years) & & 32.277 & 0.000 & & & & & 41.485 & 0.000 \\
\hline 18-39 & $34.40 \pm 10.23$ & & & $316(66.2)$ & $141(29.6)$ & $20(4.2)$ & $0(0)$ & & \\
\hline $40-59$ & $38.70 \pm 10.76$ & & & 687 (79.9) & $150(17.4)$ & $23(2.7)$ & $0(0)$ & & \\
\hline$\geq 60$ & $39.52 \pm 10.56$ & & & $292(82.7)$ & $55(15.6)$ & $6(1.7)$ & $0(0)$ & & \\
\hline Rural & $39.62 \pm 10.42$ & & & 735 (83.9) & $134(15.3)$ & $7(0.8)$ & $0(0)$ & & \\
\hline Season & & 10.125 & 0.000 & & & & & 115.759 & 0.000 \\
\hline Sumer-Autumn & $39.20 \pm 10.34$ & & & 1,027 (82.6) & $204(16.4)$ & $13(1.0)$ & $0(0)$ & & \\
\hline Winer-Spring & $33.35 \pm 10.50$ & & & $268(60.1)$ & $142(31.8)$ & $36(8.1)$ & $0(0)$ & & \\
\hline Education level & & 8.832 & 0.000 & & & & & 48.781 & 0.000 \\
\hline Low (<13 years) & $39.00 \pm 10.81$ & & & $990(81.1)$ & 203 (16.6) & $28(2.3)$ & $0(0)$ & & \\
\hline High ( $\geq 13$ years) & $34.15 \pm 9.84$ & & & $305(65.0)$ & $143(30.5)$ & $21(4.5)$ & $0(0)$ & & \\
\hline BMI $\left(k g / m^{2}\right)$ & & 2.308 & 0.075 & & & & & 11.732 & 0.068 \\
\hline Central obesity & $36.93 \pm 10.00$ & & & $540(75.8)$ & $148(20.8)$ & $24(3.4)$ & $0(0)$ & & \\
\hline Normal & $38.19 \pm 11.27$ & & & $755(77.2)$ & $198(20.2)$ & $25(2.6)$ & $0(0)$ & & \\
\hline Total cholesterol (mmol/L) & & -3.104 & 0.002 & & & & & 12.996 & 0.002 \\
\hline$<5.2$ & $36.73 \pm 10.90$ & & & $538(73.1)$ & $167(22.7)$ & $31(4.2)$ & $0(0)$ & & \\
\hline$\geq 5.2$ & $38.37 \pm 10.61$ & & & $757(79.3)$ & $179(18.8)$ & $18(1.9)$ & $0(0)$ & & \\
\hline Triglycerides (mmol/L) & & -3.312 & 0.001 & & & & & 14.065 & 0.001 \\
\hline$<1.7$ & $36.87 \pm 10.82$ & & & $684(73.7)$ & 207 (22.3) & $37(4.0)$ & $0(0)$ & & \\
\hline$\geq 1.7$ & $38.61 \pm 10.64$ & & & $611(80.2)$ & $139(18.2)$ & $12(1.6)$ & $0(0)$ & & \\
\hline
\end{tabular}

Characteristics of different groups were compared by Student's $t$-test, chi-square test, or ANOVA. $\mathrm{P}$ values $<0.05$ were considered statistically significant. BMI, body mass index; 25(OH)D, 25-hydroxyvitamin D. 
Table 3 Predictors of vitamin D sufficiency among adult residents in the Hainan Province of China

\begin{tabular}{|c|c|c|c|}
\hline Variable & OR & $95 \% \mathrm{Cl}$ & $P$ value \\
\hline \multicolumn{4}{|l|}{ Gender } \\
\hline Female & Ref. & & \\
\hline Male & 0.201 & $0.145-0.278$ & 0.000 \\
\hline \multicolumn{4}{|l|}{ Age } \\
\hline$\geq 40$ years & Ref. & & \\
\hline$<40$ years & 1.456 & $1.066-1.987$ & 0.018 \\
\hline \multicolumn{4}{|l|}{ Urbanization } \\
\hline Rural & Ref. & & \\
\hline Urban & 1.798 & $1.376-2.350$ & 0.000 \\
\hline \multicolumn{4}{|l|}{ Season } \\
\hline Winter-Spring & Ref. & & \\
\hline Summer-Autumn & 0.344 & $0.263-0.451$ & 0.000 \\
\hline \multicolumn{4}{|l|}{ Education level } \\
\hline High ( $\geq 13$ years) & Ref. & & \\
\hline Low (<13 years) & 0.504 & $0.372-0.683$ & 0.000 \\
\hline \multicolumn{4}{|l|}{ BMI } \\
\hline Underweight & Ref. & & \\
\hline Normal & 0.749 & $0.430-1.305$ & 0.308 \\
\hline Overweight & 0.926 & $0.696-1.231$ & 0.596 \\
\hline Obese & 1.074 & $0.699-1.650$ & 0.745 \\
\hline
\end{tabular}

Waist circumference

$\begin{array}{lccc}\text { Normal } & \text { Ref. } & & \\ \text { Centrally obese } & 1.137 & 0.838-1.543 & 0.410\end{array}$

Total cholesterol

$\begin{array}{lccc}\text { Normal } & \text { Ref. } & & \\ \text { Hypercholesterolemic } & 1.015 & 0.750-1.372 & 0.925\end{array}$

Triglycerides

\begin{tabular}{lccc} 
Normal & Ref. & & \\
Hypertriglyceridemia & 0.832 & $0.634-1.092$ & 0.185 \\
\hline
\end{tabular}

BMI, body mass index.

0.019, respectively; $\mathrm{P}>0.05$ ).

Binomial logistic regression analyses revealed that vitamin $\mathrm{D}$ sufficiency was strongly associated with male sex [odds ratio (OR) 0.201; $\mathrm{P}<0.0001$ ], participants $<40$ years old (OR 1.456; $\mathrm{P}=0.018)$, urban habitation $(\mathrm{OR}$
1.798; $\mathrm{P}<0.0001)$, summer-autumn season ( $\mathrm{OR}$ 0.344; $\mathrm{P}<0.0001)$, and low education level (OR 0.504; $\mathrm{P}<0.0001)$. No significant associations with vitamin $\mathrm{D}$ sufficiency were found in different serum total cholesterol, triglycerides, body mass index, or waist circumference subgroups (Table 3).

\section{Discussion}

Although vitamin D deficiency is common across the globe, data on vitamin D deficiency in Hainan, which is the only low-latitude tropical island province of China, is unknown. To our knowledge, this study is the first to conduct a crosssectional survey based on adult residents to evaluate the vitamin D status and its related factors in Hainan, China. Our study showed that the adult residents of Hainan had a mean serum $25(\mathrm{OH}) \mathrm{D}$ level of $37.66 \pm 10.77 \mathrm{ng} / \mathrm{mL}$, and $97.1 \%$ of participants had a $25(\mathrm{OH}) \mathrm{D}$ status of $>20 \mathrm{ng} / \mathrm{mL}$ between 2018 and 2020. The prevalence of vitamin D deficiency in this population was only $2.9 \%$, and we encountered no cases with $25(\mathrm{OH}) \mathrm{D}$ levels $<10 \mathrm{ng} / \mathrm{mL}$. In contrast, vitamin $\mathrm{D}$ deficiency is prevalent in inland China and worldwide $(5,6,10,18,19)$.

Vitamin D3 is produced in the skin under the influence of ultraviolet rays from the sun and is, with a smaller portion obtained from diet, thus, sufficient exposure to sunlight is crucial for the production of vitamin D3 $(18,20)$. There are several factors that may affect the production of vitamin $\mathrm{D}$ in the skin, including latitude, variation, season, daytime, pigmentation of the skin, lifestyle, dietary intake, and the use of sunscreen $(8,21,22)$. Previous studies have shown that people living in low-latitude areas may have higher serum $25(\mathrm{OH}) \mathrm{D}$ levels than those living in high-latitude areas (23), and that serum $25(\mathrm{OH}) \mathrm{D}$ levels in summer and autumn are higher than those in winter and spring (24). These results suggest that the vitamin D status of humans is largely affected by geographic location and climate. Our data showed that adult residents in Hainan had sufficient levels of vitamin $\mathrm{D}$, and the prevalence of vitamin $\mathrm{D}$ deficiency was not common in this population. These results may be due to the unique geographical location, climate, clothing style, and/or consumption of fatty fish. Hainan is located at latitude $3^{\circ} 20^{\prime}-20^{\circ} 18^{\prime} \mathrm{N}$ in the southernmost area of China, and has a tropical monsoon climate with long summers and short winters. It has an average of 1,750 to 2,650 hours of annual sunshine, little pollution, and abundant ultraviolet $\mathrm{B}$ (UVB) radiation. As the annual average temperature of Hainan is about $25.4{ }^{\circ} \mathrm{C}$, the residents on this island wear short T-shirts and shorts, which may help them receive 
more sun exposure. Another way vitamin D can be acquired is through the consumption of fish. Brustad et al. indicated that, in the coastal population of Norway at $70^{\circ} \mathrm{N}$ latitude, high vitamin $\mathrm{D}$ status might be related to the consumption of large amounts of fatty fish (25). Hainan island is rich in seafood. A survey of the dietary composition of Hainan residents showed that the intake of marine fish and shrimp is much higher than that of the national level. For example, in 1982, the intake of marine fish and shrimp from the residents was $86.4 \mathrm{~g}$ in urban areas and $72.4 \mathrm{~g}$ in rural areas; this then increased to $89.9 \mathrm{~g}$ in urban areas and to $79.7 \mathrm{~g}$ in rural areas in 2009, which is much higher than the national average of $29.6 \mathrm{~g}$ (26). Likewise, the adult residents of Hainan Province may obtain higher levels of vitamin D by eating lots of fatty fish and fish oil.

In the present study, 25(OH)D status in males was higher than that in females. Compared with females, males had a 0.201 -fold risk of vitamin D deficiency or insufficiency, with previous studies reporting consistent results $(13,21,27)$. Different hormone levels and lifestyles may be possible reasons for the difference in serum 25(OH)D levels between males and females. Males might have a higher dietary intake of vitamin D and longer sun exposure. Chinese females value having fair skin and are more likely to use sunscreen and other skin-whitening cosmetics, which have been proven to inhibit the synthesis of vitamin D3 in the skin (28-31).

A number of previous studies have shown inconsistency in the correlation between age and serum 25(OH)D levels (6,31-34). For example, studies by $\mathrm{Hu}$ et al. and Zhao et al. showed that serum $25(\mathrm{OH}) \mathrm{D}$ was negatively correlated with age $(32,33)$, whereas Yu et al. and Ning et al. reported that serum 25(OH)D levels had no correlation with age $(6,34)$. Moreover, Vieth et al. proposed that as dermal synthesis of vitamin D3 is less efficient in older persons, the production of vitamin $\mathrm{D}$ in the skin decreases with age; meanwhile, the use of $25(\mathrm{OH}) \mathrm{D}$ by the kidney may be reduced. Aging itself has no effect on serum 25(OH)D levels (35). Our data showed that s serum 25(OH)D levels of residents in Hainan increased with age and were significantly higher in the elderly and middle-aged groups than in the younger group. Rank correlation analysis showed that age was positively correlated with $25(\mathrm{OH}) \mathrm{D}$ levels; logistic regression suggested that after adjusting for gender, region, season, education level, waist circumference, body mass index, total cholesterol, triglycerides, etc., age $>40$ years was a protective factor for vitamin D. These results were consistent with the results of the general population in eastern China (36). In the Hainan province, older people are more likely to bask in the sun and less likely to use sunscreen, especially those $\geq 60$ years old, who often do outdoor activities, such as walking in parks or dancing in squares. In addition, the seasonal changes in Hainan are not as marked those as in inland China or Western countries, while the hours of sunshine in all seasons in Hainan is comparatively longer than those in inland China or Western countries. These factors may enable elderly persons in Hainan to receive more sunlight. Moreover, as age increases, the body may exhibit 1,25-dihydroxyvitamin $\mathrm{D}[1,25(\mathrm{OH}) 2 \mathrm{D}]$ resistance, which can lead to a compensatory increase in serum 25(OH)D (37), but this needs to be confirmed by further studies.

Adult residents living in rural areas of Hainan had a better $25(\mathrm{OH})$ status than did urban residents. Logistic regression showed that residents living in urban areas had a 1.798 times higher risk of vitamin D deficiency or insufficiency than those in rural areas. These results were consistent with previous studies $(23,38)$ and maybe due to air pollution, greater sunscreen use, and higher frequency of indoor activities of adult residents in urban areas compared with rural areas.

Moreover, our study found that education level of residents had an impact on serum 25(OH)D levels. Residents with a high education level ( $\geq 13$ years) had a significantly higher prevalence of vitamin $D$ deficiency than those with a lower education level ( $<13$ years), which was consistent with a previous study (39). These results suggest that residents with a higher education may be more likely to study and work indoors, participate less in outdoor activities, and use sun protection, which may lead to a reduction in sun exposure.

The present study had some limitations. First, sunlight exposure is a crucial factor of serum 25(OH)D levels; however we were not able to detect the sun exposure duration for each participant. Second, this is a descriptive cross-sectional study, the results of which can only indicate the associations between potential predictors (such as gender, age, living area, season, education level, etc.) and vitamin $\mathrm{D}$ status, but the root causes cannot be assessed. Therefore, further studies, especially those with prospective cohort designs, are needed to evaluate whether other factors (gender, age, living area, season, education level, etc.) may be reasons for the higher vitamin $\mathrm{D}$ levels observed in adult residents of Hainan Province.

In conclusion, we found vitamin D deficiency to have low prevalence in adult residents of Hainan Province, a tropical island province in China. The total prevalence of vitamin 
D deficiency in the period from 2018 to 2020 was only $2.9 \%$ ( $0 \%$ for severe deficiency). These findings suggest that vitamin $\mathrm{D}$ deficiency is not common in Hainan. Thus, before developing a strategy for the clinical use of vitamin $\mathrm{D}$ supplements in a region, the levels of vitamin $\mathrm{D}$ in the general populations of that region should be assessed. The notion that "vitamin D deficiency is widespread" should not be accepted uncritically, as this may lead to unnecessary vitamin D supplementation and escalating health care costs.

\section{Acknowledgments}

Funding: The present study was funded by the major research and development program of Hainan Province (No. ZDYF2019156) and the Hainan Province Family Planning Science and Education Health Project (No. 20A200092).

\section{Footnote}

Reporting Checklist: The authors have completed the STROBE reporting checklist Available at http://dx.doi. org/10.21037/apm-21-1033

Data Sharing Statement: Available at http://dx.doi. org/10.21037/apm-21-1033

Conflicts of Interest: All authors have completed the ICMJE uniform disclosure form (available at http://dx.doi.org/ apm-21-1033). The authors have no conflicts of interest to declare.

Ethical Statement: The authors are accountable for all aspects of the work in ensuring that questions related to the accuracy or integrity of any part of the work are appropriately investigated and resolved. The present study was approved by the Medical Ethics Committee of Hainan General Hospital [Medical ethics research (2018) no.78]. The study was in accordance with the Declaration of Helsinki (as revised in 2013). All participants gave written informed consent.

Open Access Statement: This is an Open Access article distributed in accordance with the Creative Commons Attribution-NonCommercial-NoDerivs 4.0 International License (CC BY-NC-ND 4.0), which permits the noncommercial replication and distribution of the article with the strict proviso that no changes or edits are made and the original work is properly cited (including links to both the formal publication through the relevant DOI and the license). See: https://creativecommons.org/licenses/by-nc-nd/4.0/.

\section{References}

1. Kheiri B, Abdalla A, Osman M, et al. Vitamin D deficiency and risk of cardiovascular diseases: a narrative review. Clin Hypertens 2018;22;24:9.

2. Cimini FA, Barchetta I, Carotti S, et al. Relationship between adipose tissue dysfunction, vitamin $\mathrm{D}$ deficiency and the pathogenesis of non-alcoholic fatty liver disease. World J Gastroenterol 2017;23:3407-17.

3. Gao XR, Yu YG. Meta-Analysis of the Association between Vitamin D Receptor Polymorphisms and the Risk of Autoimmune Thyroid Disease. Int J Endocrinol 2018;2018:2846943.

4. Golden NH, Abrams SA; Committee on Nutrition. Optimizing bone health in children and adolescents. Pediatrics 2014;134:e1229-43.

5. van Schoor N, Lips P. Global Overview of Vitamin D Status. Endocrinol Metab Clin North Am 2017;46:845-70.

6. Yu S, Fang H, Han J, et al. The high prevalence of hypovitaminosis D in China: a multicenter vitamin D status survey. Medicine (Baltimore) 2015;94:1.

7. Schleicher RL, Sternberg MR, Looker AC, et al. National Estimates of Serum Total 25-Hydroxyvitamin $\mathrm{D}$ and Metabolite Concentrations Measured by Liquid Chromatography-Tandem Mass Spectrometry in the US Population during 2007-2010. J Nutr2016;146:1051-61.

8. Kroll MH, Bi C, Garber CC, et al. Temporal relationship between vitamin $\mathrm{D}$ status and parathyroid hormone in the United States. PLoS One 2015;10:e0118108.

9. Cashman KD, Dowling KG, Škrabáková Z, et al. Vitamin D deficiency in Europe: pandemic? Am J Clin Nutr 2016;103:1033-44.

10. Lips P, Cashman KD, Lamberg-Allardt C, et al. Current vitamin D status in European and Middle East countries and strategies to prevent vitamin D deficiency: a position statement of the European Calcified Tissue Society. Eur J Endocrinol 2019;180:P23-54.

11. Marwaha RK, Tandon N, Chopra S, et al. Vitamin D status in pregnant Indian women across trimesters and different seasons and its correlation with neonatal serum 25-hydroxyvitamin D levels. Br J Nutr 2011;106:1383-9.

12. Shivane VK, Sarathi V, Bandgar T, et al. High prevalence of hypovitaminosis $\mathrm{D}$ in young healthy adults from the western part of India. Postgrad Med J 2011;87:514-8. 
13. Chen J, Yun C, He Y, et al. Vitamin D status among the elderly Chinese population: a cross-sectional analysis of the 2010-2013 China national nutrition and health survey (CNNHS). Nutr J 2017;16:3.

14. Man PW, van der Meer IM, Lips P, et al. Vitamin D status and bone mineral density in the Chinese population: a review. Arch Osteoporos 2016;11:14.

15. Hoseinzadeh E, Taha P, Wei C, et al. The impact of air pollutants, UV exposure and geographic location on vitamin D deficiency. Food Chem Toxicol 2018;113:241-54.

16. National Bureau of Statistics of China. Tabulation on the 2010 population census of the People's Republic of China. 2010. Available online: http://www.stats.gov.cn/tjsj/pcsj/ rkpc/6rp/indexch.htm

17. Chinese Medical Association, Chinese Medical Association Journal, Chinese Medical Association General Practice Branch, et al. Obesity Primary Diagnosis and Treatment Guidelines (2019). Chin J Gen Pract 2020;19:95-101.

18. Holick MF, Binkley NC, Bischoff-Ferrari HA, et al. Evaluation, treatment, and prevention of vitamin D deficiency: an Endocrine Society clinical practice guideline. J Clin Endocrinol Metab 2011;96:1911-30.

19. Darling AL, Blackbourn DJ, Ahmadi KR, et al. Very high prevalence of 25-hydroxyvitamin D deficiency in $6433 \mathrm{UK}$ South Asian adults: analysis of the UK Biobank Cohort. Br J Nutr202 1;125:448-59.

20. Maeda SS, Kunii IS, Hayashi L, et al. The effect of sun exposure on 25-hydroxyvitamin D concentrations in young healthy subjects living in the city of São Paulo, Brazil. Braz J Med Biol Res 2007;40:1653-9.

21. Touvier M, Deschasaux M, Montourcy M, et al. Determinants of vitamin D status in Caucasian adults: influence of sun exposure, dietary intake, sociodemographic, lifestyle, anthropometric, and genetic factors. J Invest Dermatol 2015;135:378-88.

22. Serdar MA, Batu Can B, Kilercik M, et al. Analysis of Changes in Parathyroid Hormone and $25(\mathrm{OH})$ Vitamin D Levels with Respect to Age, Gender and Season: A Data Mining Study. J Med Biochem 2017;36:73-83.

23. Mendes MM, Darling AL, Hart KH, et al. Impact of high latitude, urban living and ethnicity on 25-hydroxyvitamin D status: A need for multidisciplinary action? J Steroid Biochem Mol Biol 2019;188:95-102.

24. Shen M, Li Z, Lv D, et al. Seasonal variation and correlation analysis of vitamin $\mathrm{D}$ and parathyroid hormone in Hangzhou, Southeast China. J Cell Mol Med 2020;24:7370-7.

25. Brustad M, Sandanger T, Aksnes L, et al. Vitamin
D status in a rural population of northern Norway with high fish liver consumption. Public Health Nutr 2004;7:783-9.

26. Yang B, Pan XH, Li YZ, et al. Survey of dietary patterns and nutrients intake status of residents in Hainan. China Tropical Medicine 2009;9:1673-6,1692.

27. Feng X, Guo T, Wang Y, et al. The vitamin D status and its effects on life quality among the elderly in Jinan, China. Arch Gerontol Geriatr 2016;62:26-9.

28. Cheng S, Lian S, Hao Y, et al. Sun-exposure knowledge and protection behavior in a North Chinese population: a questionnaire-based study. Photodermatol Photoimmunol Photomed 2010;26:177-81.

29. Golan-Cohen A, Merzon E, Alhin O, et al. Blood levels of vitamin $\mathrm{D}$ and health-functional status in asymptomatic individuals: a cross sectional study. J Eval Clin Pract 2016;22:946-51.

30. Holman DM, Berkowitz Z, Guy GP Jr, et al. Patterns of sunscreen use on the face and other exposed skin among US adults. J Am Acad Dermatol 2015;73:83-92.e1.

31. Matsuoka LY, Ide L, Wortsman J, et al. Sunscreens suppress cutaneous vitamin D3 synthesis. J Clin Endocrinol Metab 1987;64:1165-8.

32. Hu Y, Chen J, Wang R, et al. Vitamin D Nutritional Status and its Related Factors for Chinese Children and Adolescents in 2010-2012. Nutrients 2017;9:1024.

33. Zhao J, Xia W, Nie M, et al. The levels of bone turnover markers in Chinese postmenopausal women: Peking Vertebral Fracture study. Menopause 2011;18:1237-43.

34. Ning Z, Song S, Miao L, et al. High prevalence of vitamin $\mathrm{D}$ deficiency in urban health checkup population. Clin Nutr 2016;35:859-63.

35. Vieth R, Ladak Y, Walfish PG. Age-related changes in the 25-hydroxyvitamin $\mathrm{D}$ versus parathyroid hormone relationship suggest a different reason why older adults require more vitamin D. J Clin Endocrinol Metab2003;88:185-91.

36. Zhen C, Ningjian W, Qin L, et al. Serum vitamin D levels of the natural population in eastern China. Chin J Endocrinol Metab 2017;33:726-9.

37. Pattanaungkul S, Riggs BL, Yergey AL, et al. Relationship of intestinal calcium absorption to 1,25-dihydroxyvitamin $\mathrm{D}(1,25(\mathrm{OH}) 2 \mathrm{D})$ levels in young versus elderly women: evidence for age-related intestinal resistance to $1,25(\mathrm{OH}) 2 \mathrm{D}$ action. J Clin Endocrinol Metab 2000;85:4023-7.

38. Song BM, Rhee Y, Kim CO, et al. Urban-rural differences explain the association between serum 25-hydroxyvitamin 
$\mathrm{D}$ level and insulin resistance in Korea. Nutrients 2014;6:5806-18

39. Lu L, Yu Z, Pan A, et al. Plasma 25-hydroxyvitamin D concentration and metabolic syndrome among middleaged and elderly Chinese individuals. Diabetes Care 2009;32:1278-83.

Cite this article as: Lin L, Ou Q, Lin L, Zhang H, Chen K, Chen D, Quan H, He Y, Fang T. Low prevalence of vitamin D deficiency in adult residents in Hainan, the tropical island province of China. Ann Palliat Med 2021;10(5):5580-5589. doi: 10.21037/apm-21-1033 